\title{
A scope of the problem: Post-deployment reintegration challenges in a National Guard Unit
}

\author{
Sherrie L. Wilcox*, Hyunsung Oh, Sarah A. Redmond, Joseph Chicas, Anthony M. Hassan, \\ Pey-Jiuan Lee and Kathleen Ell \\ Center for Innovation and Research on Veterans and Military Families (CIR), School of Social Work, University of \\ Southern California, Los Angeles, CA, USA
}

Received 8 July 2013

Accepted 5 February 2014

\begin{abstract}
.
BACKGROUND: More Reserve and Guard members have been activated in the past few years than in any other time in history. In addition to the high rates of psychological and behavioral challenges among military personnel, there are other equally important post-deployment reintegration challenges. Post-deployment reintegration challenges are particularly important to Reserve and Guard members, who transition rapidly from civilian-military-civilian.

OBJECTIVE: This study aims to describe the scope of challenges that a battalion of National Guard members (NGM) report experiencing after returning from a one-year deployment to Iraq.

METHOD: This article reports data from a sample of 126 NGM who recently returned from a one-year deployment to Iraq. The scope of post-deployment problems at baseline, 3- and 6-month post-deployment are presented.

RESULTS: Overall, the rates of post-deployment psychological and behavioral problems were elevated upon returning from deployment and remained fairly constant for up to 6 months post-deployment. Approximately $30 \%$ of respondents were unsatisfied with their relationship and upwards of $30 \%$ reported family reintegration challenges.

CONCLUSIONS: Comparisons with similar research and implications for prevention and improvement of post-deployment quality of life are addressed.
\end{abstract}

Keywords: Employment, marital relationship, reintegration, post-deployment transitioning

\section{Introduction}

More than two million military personnel have been deployed to the recent wars that are part of the Overseas Contingency Operations [1]. The National Guard is a joint reserve component of the Army and the Air Force, and has both a state and federal component.

${ }^{*}$ Corresponding author: Sherrie Wilcox, Center for Innovation and Research on Veterans and Military Families (CIR), School of Social Work, University of Southern California, 1150 S. Olive Street, Suite 1400, Los Angeles, CA 90015, USA. Tel.: +1 213821 3618; Fax: +1 213740 7735; E-mail: SLWilcox@USC.edu.
Thus, National Guard members (NGM) receive orders from both the state governor and the President of the United States. Traditionally, the National Guard has focused on domestic disaster management and emergency relief. In recent years, the National Guard has been called upon more frequently for deployments to combat zones.

NGM are unique compared to the active duty forces within the military. While active duty forces are more immersed within the military structure and culture, NGM are community-dwelling service members and typically have an established civilian life. Thus, NGM make rapid civilian-military-civilian transitions, which 
can significantly impact both their lives and their families' lives, particularly in response to a deployment. Although challenges present themselves throughout the deployment cycle, the most commonly studied problems are those that emerge in the post-deployment stage [2]. The post-deployment stage is the time where military personnel have returned home from the deployment and are reintegrating back into the family and, for NGM, community life [2]. Common post-deployment reintegration problems include mental health symptomatology, unemployment and financial problems, and family relationship difficulties [3].

\subsection{Mental health symptomatology}

Symptoms of mental health problems, including post-traumatic stress disorder (PTSD), generalized anxiety disorder (GAD), and major depressive disorder (MDD), are common among military personnel who were recently deployed [4-6]. The rates of mental health symptoms exceed those in the general population, indicating that military personnel are a high-risk population with unique needs [7-9]. Although little is reported on the mental health problems among NGM, active and reserve components report post-deployment rates of mental health problems between $2.7-35 \%$, with rates elevated in the reserve component compared to the active duty component [8]. The variability in the range is likely due to a number of factors, including branch of service, type of service (e.g., active duty, reserve), and combat exposure, among other factors [9].

Mental health problems are of particular concern for NGM, who may not live within close proximity to a military treatment facility and who often only have limited access to medical benefits $[10,11]$. Among scholarly peer-reviewed literature, rates of mental health problems among NGM range from $11 \%$ in a sample of 157 post-deployed NGM [12] to $13.8 \%$ in another sample of 522 post-deployed NGM [13], to as high as $48.5 \%$ in a sample of 97 post-deployed NGM [14]. However, relatively few NGM report seeking treatment for a mental health problem in the postdeployment stage [12], which can lead to continued mental health problems as well as exacerbation of other problems.

\subsection{Employment problems}

Another common concern for post-deployed NGM is unemployment and subsequent financial problems [15]. While some military personnel will remain on active status after a deployment, others will return to the civilian work environment or intend to return to the civilian work environment, but do not have a job waiting for them [15]. Although federal laws exist to protect the jobs of deployed military personnel, there is still a risk of losing their job from layoffs or termination of positions, leaving returning military personnel unemployed. Unemployment and job loss are significant stressors for returning NGM $[12,16]$. Interian and colleagues [12] found that 33\% of NGM assessed reported worsening job status and $20 \%$ reported losing a job or business after a deployment.

\subsection{Post-deployment alcohol misuse}

Alcohol consumption at post-deployment is normally accepted behavior in military culture [17]. There are temporary benefits, including reducing stress and promoting social activities. However, post-deployment alcohol consumption can quickly turn into alcohol misuse and the U.S. military has seen increases in alcohol misuse since 2007 [18]. Alcohol misuse is particularly common in NGM; research has found the prevalence of alcohol misuse in NGM is higher than both the general population and active duty service members $[4,19]$.

Alcohol misuse is associated with reduced combat readiness, psychological health problems, and postdeployment readjustment difficulties [17,20-22]. Other research on NGM by Kehle and colleagues [23] found that $13 \%$ reported diagnosable alcohol use disorder criteria, $73 \%$ met alcohol dependence criteria, and $27 \%$ met criteria for alcohol abuse. Additionally, those who reported alcohol misuse were more likely to report severe PTSD symptoms [23].

\subsection{Family relationship difficulties}

Upon returning from a deployment, there is typically a "honeymoon period" - a joyous reunion between the service member and family members $[2,24,25]$. However, as time passes, the immediate positive emotions from the honeymoon period become subdued as family reintegration challenges emerge. Family reintegration challenges involve role transitioning, child behavioral problems, and mismatched expectations, among others. Although deployment is a stressful event that undermines global family stability, the service member's homecoming also disrupts routines [26], which can serve as a contributor to relationship conflict.

While military personnel are deployed, family roles shift such that the non-deployed spouse/partner takes 
over roles and responsibilities usually left to the service member [2,26]. Role shifting can lead to readjustment struggles in both the service member and the nondeployed spouse/partner [27]. In the post-deployment stage, roles and responsibilities will need to be reestablished as the service member transitions back into the family unit. Role shifting can cause military personnel to feel like an outcast in their own family or feel anxious about being unable to fit into the new family roles [28,29]. The burden from role shifting is a source of emotional distress [30-32].

\subsection{Purpose of this study}

The majority of research on military populations has focused on active duty members in the primary branches of the military (i.e., Air Force, Army, Navy, and Marine Corps); relatively few studies have focused on NGM. Clearly, more data from NGM are needed to inform our understanding of the unique challenges that NGM experience and their implications for successful reintegration into the civilian community and family unit. Drawing on survey data from a sample of Army NGM, this study examines rates of commonly reported post-deployment reintegration challenges. The study aims to describe the scope of challenges that a battalion of NGM report experiencing after returning from a one-year deployment to Iraq.

\section{Method}

\subsection{Participants and procedures}

Data for this study are based on self-report surveys obtained from 126 of approximately 300 Army NGM from an aviation battalion that returned from a one-year deployment to Iraq. These data are part of a larger, multi-unit (i.e., aviation battalion, military intelligence unit) study examining reintegration challenges of NGM and their families. Survey responses were obtained at baseline (i.e., returning from the deployment) and 3, 6, 9, and 12 months post-deployment. Data in this article represent the first three data collection waves (i.e., baseline, 3 and 6 months) of the longitudinal study for the aviation battalion unit. To assess the representativeness of the sample, demographic characteristics of study participants were compared to the general National Guard population [33]. Overall, the sample was similar to the National Guard population.

\subsection{Recruitment}

The study team engaged the entire aviation battalion (i.e., "the unit") at their decompression site upon the unit's return from deployment by giving a recruitment briefing and provided an overview of the study. The research team then mailed a study packet containing informed consent and baseline assessment forms to each unit member. The study team also presented at multiple homecoming events to recruit participants. Overall, 126 unit members (42\%) provided signed informed consent and completed the baseline assessment from August 2011 to February 2012. The study was approved by the University of Southern California Institutional Review Board.

\subsection{Measures}

\subsubsection{Combat exposure}

Combat exposure was assessed using the 14-item Combat Experiences Scale (CES) from the Deployment Risk and Resiliency Inventory (DRRI) [34]. The CES is dichotomously rated and higher scores indicate more exposure to stereotypical combat experiences. Scores on the CES range from 14-28. Sample items include, "While I was deployed, I went on combat patrols or missions," and "While I was deployed, my unit engaged in battle in which it suffered casualties." The internal consistency of the CES in this sample of NGM was $\operatorname{good}(\alpha=0.84)$.

\subsubsection{PTSD symptoms}

The presence of PTSD symptoms was evaluated using the 17-item PTSD Checklist, military version (PCL-M) [35]. The items were specific to stressful military experiences. Respondents rated the frequency that each symptom had been bothersome in the past three months on a 5-point Likert scale where $1=$ "Not at all," 2 = "A little bit," 3 = "Moderately," 4 = "Quite a bit," and 5 = "Extremely." A total score was calculated by summing the items; total score for the items range from 17 to 85 . A cutoff score of 50 is typically used to indicate probable PTSD [35]. The reliability for the PCL-M in this sample was high $(\alpha=0.95)$.

\subsubsection{MDD symptoms}

Depressive symptoms were assessed with the nineitem depression scale of the Patient Health Questionnaire (PHQ-9) [36,37]. The PHQ-9 assesses the frequency of depressive symptoms in the past two weeks. Items were rated on a 4-point Likert scale ranging from 
$0-3$, where $0=$ "not at all," $1=$ "several days," $2=$ "more than half the days," and 3 = "nearly every day." A total score was calculated by summing the items and range from 0 to 27. Greater scores indicate more depressive symptoms where scores ranging from 5-9 represent mild depression symptoms, 10-14 major depression, 15-19 moderately severe major depression, and greater than or equal to 20 severe major depression [37]. Previous research has provided evidence of its reliability and validity in different groups, including deployed veterans [38]. The reliability for the PHQ-9 in this sample was high $(\alpha=0.84)$.

\subsection{4. $G A D$}

Anxiety symptoms were assessed using the GAD7 [39]. This measure consists of seven items assessing frequency of anxiety symptoms in the past two weeks. Items were rated on a 4-point Likert scale ranging from $0-3$, where $0=$ "not at all," $1=$ "several days," $2=$ "more than half the days," and 3 = "nearly every day." A total score was calculated by summing the items; total score for the items range from 0 to 21 . Higher scores indicate greater anxiety levels and scores ranging from 0-4 represent minimal anxiety, 5-9 mild anxiety, 1014 moderate anxiety, and 15-21 severe anxiety [39]. The GAD-7 has excellent internal consistency (Cronbach's alpha $=0.92$ ) [39]. The reliability for GAD-7 in this sample was high $(\alpha=0.92)$.

\subsubsection{Aggression}

Aggression was assessed using the interpersonal aggression and conflict subscale from the Post-Deployment Health Assessment (PDHA) and Post-Deployment Health Re-Assessment (PDHRA) [40]. It consists of three yes/no questions: an interpersonal aggression item, "have you had thoughts or concerns that you might hurt or lose control with someone," and two existence of interpersonal conflict items, "have you had thoughts or concerns that you may have serious conflicts with your spouse, family members, or close friends," and "since return from deployment have you had serious conflicts with your spouse, family members, close friends, or at work that continue to cause you worry or concern?" Higher scores indicate higher levels of aggression and range from 3 to 6 . Individuals reporting two or more aggressive items were considered to have high levels of aggression. The internal consistency of the assessment in this study ranged from $0.65-0.73$.

\subsubsection{Employment status}

Employment status was assessed with two questions. The first question asked whether the NGM was currently employed and the second question asked whether the respondent expected to be employed in the next six months. These two questions were answered either "yes" or "no".

\subsubsection{Alcohol problems}

Alcohol problems were assessed using the 4-item CAGE Questionnaire. Sores range from 4-8, where higher scores indicate alcohol misuse. Respondents indicate whether or not they have engaged in the items using a yes or no response. Rating positive on two or more items is indicative of a possible alcohol problem [41]. However, one positive item on CAGE can capture behavioral issues related to alcohol misuse [19]. CAGE has been evaluated for its psychometrical properties as well as clinical value for diagnosing possible alcohol-related disorder $[41,42]$. The reliability of the CAGE in this sample was modest ( $\alpha=$ 0.54-0.67).

\subsubsection{Relationship satisfaction}

Relationship satisfaction was assessed in all participants using the eight-item Navy Quality of Life Survey Marriage/Intimate Relationship Satisfaction Scale (NQOLS-MIRS) [43]. The NQOLS-MIRS uses a 7point Likert scale to assess respondent's satisfaction with various aspects of intimate relationship, including: understanding, communication, conflicts, support, compatibility, respect, intimacy, and time away from home. Scores range from 8-56 and higher scores on the NQOLS-MIRS indicated greater marital satisfaction. Scores of 40 or higher were used to indicate marital satisfaction. The NQOLS-MIRS has high reliability ( $\alpha=0.92$ ) in other research [44]. The reliability for the NQOLS-MIRS in this sample was also high ( $\alpha=$ 0.90-0.94).

\subsubsection{Family reintegration challenges}

Family relationship challenges were assessed using items from the psychosocial problem assessment among military families [45]. For this study, the research team grouped family reintegration challenges consisting of three subsections: family post-deployment readjustment challenges $(\alpha=0.75-0.82 ; 7$ items), common post-deployment stressors ( $\alpha=0.67-$ $0.73 ; 9$ items), and child behavioral problems ( $\alpha=$ $0.72-0.75 ; 4$ items). Participants were asked to rate whether the items affected them. Scores on the full 
scale ranged from $20-40$, where a higher score indicated greater levels of family reintegration challenges. The internal consistency on the full scale was good $(\alpha=0.84-0.88)$.

\subsection{Analysis}

Data were analyzed in SPSS version 20. Descriptive statistics were used to present prevalence of the sample characteristics (i.e., demographics and psychosocial challenges). Paired samples t-tests were used to examine differences in the psychosocial challenges from baseline to 3 and 6 months post-deployment.

\section{Results}

\subsection{Sample demographics and representativeness}

The research team compared the demographic characteristics of the studied 126 Army NGM to the 2010 Army National Guard population. The demographic characteristics of participants in this study were similar to the National Guard population. As indicated in Table 1, participants were 33.15 years old on average $(S D=8.76)$ and were predominantly male $(88.4 \%)$. With respect to age, sex, and military grade, our study sample was similar to the Army National Guard population [33]. However, the study participants tended to be more ethnically diverse, more educated, and were slightly more likely to be married compared to the general population of Army NGM.

\subsection{Outcomes at Baseline, 3-month, and 6-month post-deployment}

\subsubsection{Combat exposure assessed at baseline}

The level of combat exposure was low ( $M=$ $16.76, S D=2.59$ ), indicating that the unit experienced few stereotypical combat experiences. The most commonly reported item was receiving hostile incoming fire from small arms, artillery, rockets, mortars, or bombs $(91.7 \%)$.

\subsubsection{PTSD symptoms}

In terms of PTSD symptoms, $4.1 \%$ of the baseline sample of NGM met screening criteria for probable PTSD $(M=26.41, S D=11.49)$. The rate of PTSD symptoms was similar at 3 months (5.7\% probable PTSD; $M=26.48, S D=12.72)$ and 6 months (6.2\% probable PTSD; $M=26.83, S D=10.69)$ postdeployment.

\subsubsection{Anxiety symptoms}

For anxiety symptoms at baseline, $11.4 \%$ of NGM reported moderate to severe anxiety symptoms $(M=$ $4.33, S D=4.65)$. The rate of anxiety symptoms for 3 months $(6.6 \%$ moderate-severe; $M=3.50, S D=$ 3.79 ) and 6 months (4.6\% moderate-severe; $M=3.39$, $S D=3.40)$ decreased over time.

\subsubsection{Depressive symptoms}

Compared to baseline, depressive symptoms were slightly higher at 3 months, but decreased at 6 months. Ten NGM $(8.2 \%)$ had major to severe major depression $(M=4.09, S D=4.17)$ at baseline, $12.1 \%$ at 3 months $(M=4.25, S D=4.35)$, and $7.9 \%$ at 6 months $(M=$ 4.03, $S D=4.11)$.

\subsubsection{Aggression}

Regarding aggression, at baseline the average aggression score was $3.50(S D=0.90)$. Approximately $12.2 \%$ of the NGM had thoughts/concerns that they might hurt or lose control with someone (item 1); $17.9 \%$ had thoughts/concerns that they might have serious conflicts with their spouse, family, or close friends (item 2); and $19.5 \%$ reported serious conflicts with their spouse, family members, close friends, or at work that continue to cause worry or concern since returning from the deployment (item 3). At baseline, $26.8 \%$ reported at least one aggressive behavior and $17.9 \%$ reported two or more aggressive behaviors. The rates of aggression were similar at 3 and 6 months. Item 3 was consistently the most commonly selected item. Follow-up data are presented in Table 2.

\subsubsection{Employment problems}

In terms of post-deployment employment challenges, 39.2\% ( $n=49)$ of the NGM reported being unemployed at baseline; $16.9 \%(n=21)$ expected to be unemployed in the next 6 months; $12.9 \%(n=16)$ have been behind in rent or mortgage payments. The unemployment rate improved $11.9 \%$ from baseline to 6-months post-deployment, although $3.8 \%$ more NGM reported being behind in rent/mortgage at 6 months.

\subsubsection{Alcohol problems}

At baseline, 20.7\% of NGM were positive on at least one of the CAGE items, and $9.9 \%$ NGM were positive on two or more of the CAGE items. Most NGM did not report problems with alcohol at baseline (79.3\%). The rates of NGM with at least one positive CAGE and two or more positive CAGE items remained consistent over the 6-month observation time frame. 
Table 1

Sample demographics and representativeness

\begin{tabular}{|c|c|c|}
\hline Characteristic & $\begin{array}{l}\text { Service members: } \\
\text { Aviation battalion } \\
\quad(N=126) \\
n(\%)\end{array}$ & $\begin{array}{c}2011 \text { Army NGM: } \\
\text { (Selected reserve) } \\
(N=361,561) \\
n(\%)\end{array}$ \\
\hline \multicolumn{3}{|l|}{ Age } \\
\hline 25 or younger & $26(20.6)$ & $144,228(39.9)$ \\
\hline $26-30$ & $24(19.1)$ & $68,239(18.9)$ \\
\hline $31-35$ & $19(15.1)$ & $43,386(12.0)$ \\
\hline $36-40$ & $17(13.5)$ & $37,028(10.2)$ \\
\hline 41 or older & $26(20.6)$ & $68,680(19.0)$ \\
\hline Missing & $14(11.1)$ & 0 \\
\hline \multicolumn{3}{|l|}{ Sex } \\
\hline Male & $99(78.6)$ & $308,851(85.4)$ \\
\hline Female & $13(10.3)$ & $52,707(14.6)$ \\
\hline Missing & $14(11.1)$ & 0 \\
\hline \multicolumn{3}{|l|}{ Race } \\
\hline White & $68(54)$ & $290,729(80.4)$ \\
\hline Black & $5(4)$ & $47,953(13.3)$ \\
\hline Asian & $12(9.5)$ & $9,209(2.6)$ \\
\hline Pacific Islander & $2(1.6)$ & NA \\
\hline Native American & $4(3.2)$ & $2,758(0.8)$ \\
\hline Other & $35(27.8)$ & $10,912(3.0)$ \\
\hline \multicolumn{3}{|l|}{ Ethnicity } \\
\hline Hispanic & $63(50)$ & NA \\
\hline Non-Hispanic & $49(38.9)$ & NA \\
\hline Missing & $14(11.1)$ & NA \\
\hline \multicolumn{3}{|l|}{ Education } \\
\hline High-school graduate or less & NA & $11,487(3.2)$ \\
\hline Some college & $62(49.2)$ & $291,207(80.5)$ \\
\hline College graduate or higher & $46(36.5)$ & $57,961(16.0)$ \\
\hline Other/missing & $18(14.3)$ & $906(0.3)$ \\
\hline \multicolumn{3}{|l|}{ Marital status } \\
\hline Single & $36(28.6)$ & NA \\
\hline Married & $65(51.6)$ & $160,113(44.3)$ \\
\hline Divorced/separated & $11(8.7)$ & NA \\
\hline Missing & $14(11.1)$ & NA \\
\hline \multicolumn{3}{|l|}{ Children } \\
\hline Yes & $80(63.5)$ & $153,254(42.4)$ \\
\hline No & $46(36.5)$ & $208,307(57.6)$ \\
\hline \multicolumn{3}{|l|}{ Military grade } \\
\hline \multicolumn{3}{|l|}{ Enlisted personnel } \\
\hline E1-E4 & $38(30.2)$ & $179,555(49.7)$ \\
\hline E5-E6 & $33(26.2)$ & $106,016(29.3)$ \\
\hline E7-E9 & $11(8.7)$ & $32,402(9.0)$ \\
\hline Officer (O1-O10) & $16(12.7)$ & $35,358(9.8)$ \\
\hline Warrant officer & $11(8.7)$ & $8,230(2.3)$ \\
\hline Missing & $17(13.5)$ & 0 \\
\hline
\end{tabular}

\subsubsection{Relationship satisfaction}

At baseline, relationship satisfaction levels were fairly high $(M=45.23, S D=9.62) ; 75.7 \%$ were satisfied with their relationship, $78.9 \%$ agreed that they have a good relationship, and $44.4 \%$ reported that their relationship increased their ability to perform their job. At 3 months, relationship satisfaction was reduced $7 \%$ compared to baseline. However, relationship satisfaction levels improved $3.3 \%$ at 6 months compared to 3 months.

\subsubsection{Family reintegration challenges}

Regarding family reintegration challenges, $21.4 \%$ reported a high level (11 or more) of overall family reintegration challenges $(M=26.20, S D=4.53)$; $13.9 \%$ reported 2 or more child behavioral problems $(M=5.21, S D=1.35) ; 34.7 \%$ reported 4 or more family post-deployment readjustment problems $(M=$ $9.60, S D=2.06$ ); and $34.7 \%$ report 5 or more of the common post-deployment stressors $(M=11.42, S D$ $=2.20$ ). While 3 -month post-deployment rates of fam- 
Table 2

Baseline, 3- and 6-month post-deployment status

\begin{tabular}{lccc}
\hline Variable & Baseline & 3 -month & 6 -month \\
\hline PTSD Symptoms $(M, S D)$ & $26.41,11.49$ & $26.48,12.72$ & $26.83,10.69$ \\
Probable PTSD & $4.1 \%$ & $5.7 \%$ & $6.2 \%$ \\
Anxiety Symptoms $(M, S D)$ & $4.33,4.65$ & $3.50,3.79$ & $3.39,3.40$ \\
Moderate-Severe Symptoms & $11.4 \%$ & $6.6 \%$ & $4.6 \%$ \\
Depression Symptoms $(M, S D)$ & $4.09,4.17$ & $4.25,4.35$ & $4.03,4.11$ \\
Major-Severe Symptoms & $8.2 \%$ & $12.1 \%$ & $7.9 \%$ \\
Aggression $(M, S D)$ & $3.50,0.90$ & $3.67,1.00$ & $3.44,0.82$ \\
Item 1 & $12.2 \%$ & $19.8 \%$ & $10.9 \%$ \\
Item 2 & $17.9 \%$ & $19.8 \%$ & $17.5 \%$ \\
Item 3 & $19.5 \%$ & $27.5 \%$ & $17.5 \%$ \\
1+ Positive Items & $26.8 \%$ & $37.4 \%$ & $27 \%$ \\
2+ Positive Items & $17.9 \%$ & $20.9 \%$ & $14.3 \%$ \\
Employment & & & \\
Unemployed & $39.2 \%$ & $30.4 \%$ & $\mathrm{NA}$ \\
Expect to be unemployed & $16.9 \%$ & $25 \%$ & $\mathrm{NA}$ \\
Behind in rent/mortgage & $12.9 \%$ & $10.9 \%$ & $16.7 \%$ \\
Alcohol problems & & & \\
CAGE Score $(M, S D)$ & $4.32,0.70$ & $4.32,0.73$ & $4.38,0.83$ \\
1+ Item & $20.7 \%$ & $19.8 \%$ & $21.9 \%$ \\
2+ Items & $9.9 \%$ & $8.8 \%$ & $10.9 \%$ \\
Relationship satisfaction & & & \\
Satisfaction Score $(M, S D)$ & $45.23,9.62$ & $42.75,10.88$ & $44.48,9.25$ \\
Relationship Satisfaction & $75.7 \%$ & $68.7 \%$ & $72 \%$ \\
Have a good relationship & $78.9 \%$ & $72 \%$ & $75.5 \%$ \\
Improve job performance & $44.4 \%$ & $39.8 \%$ & $42.3 \%$ \\
Family reintegration challenges & & & \\
Family readjustment $(M, S D)$ & $9.60,2.06$ & $10.09,2.31$ & $8.94,2.03$ \\
High Score $(4+$ items) & $34.7 \%$ & $43.6 \%$ & $28.1 \%$ \\
Common stressors $(M, S D)$ & $11.42,2.20$ & $12.91,2.31$ & $11.47,1.99$ \\
High Score $(5+$ items) & $13.9 \%$ & $26.5 \%$ & $11.6 \%$ \\
Child behavioral problems $(M, S D)$ & $5.21,1.35$ & $5.46,1.46$ & $5.12,1.36$ \\
High Score $(2+$ items) & $34.7 \%$ & $37.7 \%$ & $31.7 \%$ \\
FRC total $(M, S D)$ & $26.20,4.53$ & $27.36,5.15$ & $25.59,4.23$ \\
High Score $(11+$ items) & $21.4 \%$ & $29.5 \%$ & $10.3 \%$ \\
\hline & & &
\end{tabular}

ily reintegration challenges increased, 6-month postdeployment rates declined below baseline rates. Details are presented in Table 2.

\subsection{Post-deployment psychological, behavioral problems, and reintegration challenges over time}

\subsubsection{Mental and behavioral health problems}

A paired samples $t$ test indicated that mental and behavioral challenges were only significantly different for anxiety symptoms between baseline and 3 months, $t(89)=3.38, p=0.001, d=0.35$, and for aggression between 3 and 6 months, $t(55)=2.22, p=0.03, d=$ 0.29 . Specifically, respondents reported more anxiety symptoms at baseline $(M=4.74, S D=4.82)$ compared to 3-months $(M=3.52, S D=3.81)$, and reported higher levels of aggression at 3 months $(M=$ $5.38, S D=1.02)$ compared to 6 months $(M=5.64$, $S D=0.72$ ). Using Cohen's [46] guidelines, the differences were medium-small for anxiety and small for aggression.

\subsubsection{Alcohol problems}

A paired samples $t$ test indicated that alcohol problems were not significantly different across the postdeployment time points.

\subsubsection{Employment problems}

A paired samples $t$ test indicated that employment problems were only significantly different between baseline and 3 months for current unemployment, $t$ $(91)=2.0, p=0.05, d=0.22$, and between 3 and 6 months for being behind in a rent or mortgage payments, $t(59)=2.32, p=0.02, d=0.30$. The differences, although statistically significant, are small. Specifically, respondents were more likely to be unemployed at baseline compared to 3 months $(M=1.62$, $S D=0.49)$, and were also more likely to be behind in rent or mortgage payments at 6 months $(M=1.83$, $S D=0.38)$ compared to 3 months $(M=1.92, S D=$ $0.28)$. 


\subsubsection{Relationship satisfaction}

A paired samples $t$ test indicated that relationship satisfaction was only significantly different between baseline and 3 months, $t(76)=2.11, p=0.04$, $d=0.24$. Specifically, respondents were more satisfied with their relationship at 3 months $(M=21.20, S D=$ 10.76) compared to baseline $(M=18.96, S D=9.42)$. The differences were small.

\subsubsection{Family reintegration challenges}

A paired samples $t$ test indicated that family reintegration challenges were only significantly different for family post-deployment readjustment problems between baseline and 3 months, $t(60)=2.62, p=0.01$, $d=0.34$, and for child behavioral problems between 3 and 6 months, $t(35)=2.06, p=0.04, d=0.34$. Specifically, respondents reported more family reintegration challenges at baseline $(M=2.52, S D=1.90)$ compared to 3 months $(M=3.23, S D=2.25)$, and more child behavioral problems at 6 months $(M=$ $1.02, S D=1.36)$ compared to 3 months $(M=1.34$, $S D=1.35)$. The differences were medium-small.

\section{Discussion}

National Guard members are at risk for a number of post-deployment challenges; research has continued to document that NGM report more problems than active duty populations. The purpose of this article is to present a scope of problems that NGM experience after returning from a combat deployment. Even in a unit with low combat exposure, we found a number of potential problems, including mental health symptoms, alcohol misuse, and relationship difficulties. Unemployment rates were also potentially problematic.

Anxiety, depression, PTSD, and alcohol misuse are all related to reduced work productivity [47]. Additionally, symptoms of behavioral and mental health problems in military populations are related to decreased functioning at work, greater job turnover and loss, more missed work days, premature retirement, and more work limitations [48]. Additionally, although mental health symptomatology may impair functioning at work, it does not necessarily influence likeliness of employment $[48,49]$.

The rates of post-deployment mental health and behavioral problems vary highly across military branches, although National Guard populations tend to report more problems [7]. For example, Gorman and colleagues [50] found that $40 \%$ of the 332 NGM in their sample reported at least one mental health issue. Other research by Milliken and colleagues [40] found that NGM (and reservists) reported more mental health symptoms than active duty military personnel. This trend was also confirmed in research by Hoge and colleagues [51], where NGM reported higher rates of mental health symptoms than active duty members.

Although this study did not compare NGM to active duty branches, the rates of mental health symptoms were similar to previous research, albeit slightly lower compared to other studies. However, the mental health symptoms that emerged upon homecoming were maintained until at least six months postdeployment, despite the low levels of combat exposure. While this sample reported relatively low levels of mental health symptoms, the rate of reported anxiety symptoms was higher than the lifetime prevalence of GAD in the general population $(5.7 \%)$ and the prevalence of major-severe depressive symptoms ranged from $8 \%-12 \%$, which is higher than the 12month prevalence of MDD in the general population of adults in the U.S. (6.7\%) [52]. Moreover, the high rates of post-deployment aggression were startling and persisted through six months post-deployment. Aggression should not be overlooked in NGMs. The prevalence of aggression was approximately 2.5 times higher than that of NGM and reservists and five times higher than that of active duty forces [40]. Other research has found approximately $30 \%$ of NGM reporting that they had ever threatened someone with physical violence after returning home from a deployment [40,53].

Although the rates of reported mental and behavioral health problems in this sample remained fairly constant from immediately post-deployment to 6-months post-deployment, other research on NGM has found that rates of mental health problems, specifically PTSD symptoms, tend to increase significantly from baseline to 6-months post-deployment [40]. Moreover, high rates of post-deployment mental health symptoms are not exclusive to NGM, as spouses are also at risk for post-deployment mental health symptoms. Gorman and colleagues [50] found that $34 \%$ of 212 nondeployed partners of NGM reported at least one mental health issues after a deployment. While this article did not present mental health problems in the nondeployed spouses, research notes the importance of the military spouses' mental health. Military spouses with depression or other mental health symptoms may be less welcoming to their returning service member and make the reintegration process more challenging [54]). 
Social support, particularly from the spouse, and supportive relationships, are often conceptualized as protective factors against post-deployment mental health problems [55]. Additionally, post-deployment psychological maladjustment is an indicator of postdeployment family readjustment difficulties [14,56]. While the rates of mental and behavioral problems were slightly elevated in our sample, marital satisfaction levels were acceptable and family readjustment challenges were moderate. Marital problems and changes within the relationship are commonly reported by NGM. Kline and colleagues [57] found that of 1,665 NGM who recently returned from Iraq, $18.4 \%$ reported problems with their marriage and $11 \%$ reported separating or getting a divorce.

Interestingly, partners are more inclined to seek treatment for mental health problems than the veterans themselves. Treatment seeking by the non-veteran partner is particularly important for military children. Verdeli [54] found that lower mental health quality of military spouses (i.e., mothers) may lead to more mental health problems in military children. Other research has demonstrated that PTSD is both directly tied to parenting quality and indirectly related to parenting quality by impacting the relationship adjustment [58].

National Guard members are also at risk for alcohol misuse and unemployment. The rate of alcohol misuse in our sample was approximately $20 \%$ and between $30-40 \%$ reported unemployment. Research by Milliken and colleagues [40] found that National Guard and Reserve populations reported higher levels of alcohol misuse than active duty populations. Research on the general population indicates that alcohol use influences employment. Specifically, alcohol misuse can lead to reduced employment and increased unemployment [59]. While active duty military personnel have more job security, many NGM need to seek civilian employment after a deployment, in addition to adjusting to their family members, who have established new routines during the deployment $[16,29]$. Kline and colleagues [30] found that $11.1 \%$ of 1665 NGM reported losing a job or business after returning from a deployment to Iraq. These findings were further supported by other research finding approximately $10 \%$ of more than 4,000 post-deployed NGM reported being fired after a deployment [60]. Thus, for military personnel, while the post-deployment culture can be accepting of alcohol consumption, it can lead to alcohol misuse, which may lead to unemployment, among other problems.

Our study had several limitations. First, we did not assess pre-deployment mental and behavioral health problems. It is possible that the problems reported at post-deployment were present pre-deployment and were not directly a result of deployment. Research has already suggested that military personnel are at risk for problems across the deployment cycle, from predeployment to post-deployment [2]. Second, we collected self-report data of mental and behavioral health problems, which might be subject to bias [61].

This article adds further evidence to the challenges that NGM face upon returning from a deployment, even with low levels of combat exposure. Preparing service members for post-deployment and to reintegrate back into the civilian world after completing military service should begin as early as possible [2]. Prevention of post-deployment and other reintegration challenges should be an important component of pre-deployment preparation and training for military personnel. To reduce the burden on workplace efficiency from post-deployment and reintegration challenges, particular emphasis should be placed on reducing aggression, anxiety, and relationship difficulties, as well as increasing attractive employment opportunities and strengthening the marital relationship.

\section{References}

[1] Belasco A. Troop Levels in the Afghan and Iraq Wars, FY2001-FY2012: Cost and Other Potential. Congressional Research Service; July 2, 2009.

[2] Wilcox SL, Rank MG. Transitioning through the deployment cycle. In: Moore B, Barnett J, editors. Military Psychologists' Desk Reference. New York, NY: Oxford University Press, 2013, pp. 306-11.

[3] Hazle M, Wilcox SL, Hassan AM. Helping veterans and their families fight on! Advances in Social Work. 2012;13(1):22942.

[4] Eisen SV, Schultz MR, Vogt D, Glickman ME, Elwy AR, Drainoni M-L, et al. Mental and Physical Health Status and Alcohol and Drug Use Following Return From Deployment to Iraq or Afghanistan. American Journal of Public Health. 2012;102(S1):S66-S73.

[5] Hoge CW, Castro CA, Messer SC, McGurk D, Cotting DI, Koffman RL. Combat duty in Iraq and Afghanistan, mental health problems, and barriers to care. New England Journal of Medicine. 2004;351(1):13-22.

[6] Tanielian T, Jaycox LH, Schell TL, Marshall GN, Burnam MA, Eibner C, et al. Invisible Wounds of War: Summary and Recommendations for Addressing Psychological and Cognitive Injuries. Santa Monica, CA: RAND Corporation; 2008. p. 64.

[7] Williamson V, Mulhall E. Invisible wounds: Psychological and neurological injuries confront a new generation of veterans. January 2009. Available from: http://iava.org/files/IAVA_ invisible_wounds_0.pdf.

[8] Armed Forces Health Surveillance Center. Deployment Health Assessments U.S. Armed Forces: July 2012. Washington, DC: Defense Medical Surveillance System; July 2012. 
[9] Wilcox SL, Finney K, Cederbaum JA. Prevalence of Mental Health Problems among Military Populations. In: Moore B, Barnett J, editors. Military Psychologists' Desk Reference. New York, NY: Oxford University Press; 2013. p. 187-92.

[10] Gorman LA, Blow AJ, Ames BD, Reed PL. National Guard Families After Combat: Mental Health, Use of Mental Health Services, and Perceived Treatment Barriers. Psychiatric Services. 2011;62(1):28-34.

[11] Straits-Tröster KA, Brancu, M, Goodale, B, Pacelli, S, Wilmer, C, Simmons, EM, et al. Developing community capacity to treat post-deployment mental health problems: A public health initiative. Psychological Trauma: Theory, Research, Practice, and Policy. 2011;3(3):283-91.

[12] Interian A, Kline A, Callahan L, Losonczy M. Readjustment Stressors and Early Mental Health Treatment Seeking by Returning National Guard Soldiers With PTSD. Psychiatric Services. 2012;63(9):855-61.

[13] Polusny MA, Erbes CR, Murdoch M, Arbisi PA, Thuras $\mathrm{P}$, Rath MB. Prospective risk factors for new-onset posttraumatic stress disorder in National Guard soldiers deployed to Iraq. Psychological Medicine. 2011;41(4):687-98.

[14] Khaylis A, Polusny MA, Erbes CR, Gewirtz AH, Rath COLM. Posttraumatic stress, family adjustment, and treatment preferences among National Guard Soldiers deployed to OEF/OIF. Military Medicine. 2011;176(2):126-31.

[15] Elbogen EB, Johnson SC, Wagner HR, Newton VM, Beckham JC. Financial well-being and postdeployment adjustment among iraq and afghanistan war veterans. Military Medicine. 2012;177(6):669-75.

[16] Burnett-Zeigler I, Valenstein M, Ilgen M, Blow AJ, Gorman LA, Zivin K. Civilian employment among recently returning Afghanistan and Iraq National Guard veterans. Military Medicine. 2011;176(6):639-46.

[17] Verrall NG. A review of military research into alcohol consumption. Journal of the Royal Army Medical Corps. 2011; 157(2):164-9.

[18] Armed Forces Health Surveillance Center. Alcohol-related diagnoses, active component, U.S. armed forces, 20012010. Medical Surveillance Monthly Report. 2011, October; 18(10):9-13.

[19] Jacobson IG, Ryan MAK, Hooper TI, Smith TC, Amoroso PJ, Boyko EJ, et al. Alcohol Use and Alcohol-Related Problems Before and After Military Combat Deployment. JAMA: The Journal Of The American Medical Association. 2008;300(6): 663-75.

[20] Conner KR, Pinquart M, Gamble SA. Meta-analysis of depression and substance use among individuals with alcohol use disorders. Journal of Substance Abuse Treatment. 2009;37(2):127-37.

[21] Hasin DS, Stinson FS, Ogburn E, Grant BF. Prevalence, correlates, disability, and comorbidity of DSM-IV alcohol abuse and dependence in the United States: Results from 842the national epidemiologic survey on alcohol and related conditions. Archives of General Psychiatry. 2007;64(7):830-42.

[22] Marshal MP. For better or for worse? the effects of alcohol use on marital functioning. Clinical Psychology Review. 2003;23(7):959-97.

[23] Kehle SM, Ferrier-Auerback AG, Meis LA, Abrisi PA, Erbes CR, Polusny MA. Predictors of postdeployment alcohol use disorders in National Guard soldiers deployed to Operation Iraqi Freedom. Psychology of Addictive Behaviors. 2012;26(1):42-50.

[24] Pincus S, Leiner B, Black N, Ward Singh T. The impact of deployment on military families and children. In: Lenhart MK, editor. Textbooks of military medicine: Combat and operational behavioral health. Washington, DC: Office of The Surgeon General; 2011. p. 487-99.

[25] Pincus S, House R, Christensen J, Adler L. The emotional cycle of deployment: A military family perspective. Journal of the Army Medical Department. 2001:615-23.

[26] Sheppard SC, Malatras JW, Israel AC. The Impact of Deployment on U.S. Military Families. American Psychologist. 2010;65(6):599-609.

[27] Faber AJ, Willerton E, Clymer SR, MacDermid SM, Weiss HM. Ambiguous absence, ambiguous presence: A qualitative study of military reserve families in wartime. Journal of Family Psychology. 2008;22(2):222-30.

[28] Weins TW, Boss P. Maintaining family resiliency before, during, and after military separation. In: Castro CA, Adler AB, Britt CA, editors. Military life: The psychology of serving in peace and combat. 3. Bridgeport, CT: Praeger Security International; 2006. p. 13-38.

[29] Sayers SL, Farrow VA, Ross J, Oslin DW. Family problems among recently returned military veterans referred for a mental health evaluation. Journal of Clinical Psychiatry. 2009;70(2):163-70.

[30] Kline A, Ciccone DS, Falca-Dodson M, Black CM, Losonczy M. Suicidal ideation among national guard troops deployed to iraq: The association with postdeployment readjustment problems. Journal of Nervous and Mental Disease. 2011;199(12):914-20.

31] Lane ME, Hourani LL, Bray RM, Williams J. Prevalence of perceived stress and mental health indicators among reservecomponent and active-duty military personnel. American Journal of Public Health. 2012;102(6):1213-20.

[32] Meis LA, Erbes CR, Polusny MA, Compton JS. Intimate relationships among returning soldiers: the mediating and moderating roles of negative emotionality, PTSD symptoms, and alcohol problems. Journal of Traumatic Stress. 2010;23:56472.

[33] Department of Defense. Demographics 2010: Profile of the Military Community. Washington, DC: Department of Defense; 2010.

[34] King DW, King LA, Vogt DS. Manual for the Deployment Risk and Resilience Inventory (DRRI): A Collection of Scales for Studying Deployment-Related Experiences in Military Veterans. Boston, MA: National Center for PTSD; 2003.

[35] Weathers F, Litz B, Herman D, Huska J, Keane T. The PTSD Checklist: Reliability, validity and diagnostic utility. Annual Convention of the International Society for Traumatic Stress Studies, San Antonio, TX1993.

[36] Spitzer RL, Williams JB, Kroenke K, Linzer M, deGruy FV, III, Hahn SR, et al. Utility of a New Procedure for Diagnosing Mental Disorders in Primary Care: The PRIME-MD 1000 Study. JAMA: Journal of the American Medical Association. 1994;272(22):1749-56

[37] Spitzer RL, Kroenke K, Williams JB. Validation and utility of a self-report version of PRIME-MD: the PHQ Primary Care Study. JAMA: Journal of the American Medical Association. 1999;282:1737-44.

[38] Dum M, Pickren J, Sobell LC, Sobell MB. Comparing the BDI-II and the PHQ-9 with outpatient substance abusers. Addictive Behaviors. 2008;33(2):381-7.

[39] Spitzer RL, Kroenke K, Williams JB, Lowe B. A Brief Measure for Assessing Generalized Anxiety Disorder: The GAD7. Archives of Internal Medicine. 2006;166(10):1092-7.

[40] Milliken CS, Auchterlonie JL, Hoge CW. Longitudinal assessment of mental health problems among active and re- 
serve component soldiers returning from the Iraq war. JAMA: Journal of the American Medical Association. 2007;298(18): 2141-8.

[41] Dhalla S, Kopec JA. The CAGE questionnaire for alcohol misuse: A review of reliability and validity studies. Clinical \& Investigative Medicine. 2007;30(1):33-41.

[42] Ewing JA. Detecting alcoholism. Journal of the American Medical Association. 1984;252(14):1905-7.

[43] Wilcove GL. Results of the Navy Quality of Life Survey. In: Navy Personnel Research S, and Technology Department, editor. Millington, TN: Bureau of Navy Personnel; May 2005.

[44] Meis LA, Barry RA, Kehle SM, Erbes CR, Polusny MA. Relationship Adjustment, PTSD Symptoms, and Treatment Utilization Among Coupled National Guard Soldiers Deployed to Iraq. Journal of Family Practice. 2010;24(5):560-7.

[45] Schell TL, Tanielian T. A Needs Assessment of New York State Veterans: Final Report to the New York State Health Foundation. Santa Monica, CA: RAND Corporation; 2011.

[46] Cohen J. Statistical power analysis for the behavioral sciences. 2nd ed. Hillsdale, NJ: Lawrence Erlbaum Associates; 1988.

[47] Adler DA, Klaus J, Possemato K, Tew JD, Mavandadi S, Barrett D, et al. Psychiatric status and work performance of Veterans of Operations Enduring Freedom and Iraqi Freedom. Psychiatric Services. 2011;62(1):39-46.

[48] Erbes CR, Kaler ME, Schult T, Polusny MA, Arbisi PA. Mental health diagnosis and occupational functioning in National Guard/Reserve veterans returning from Iraq. Journal of Rehabilitation Research \& Development. 2011;48(10):1159-70.

[49] Lerner D, Henke RM. What does research tell us about depression, job performance, and work productivity? Journal of Occupational \& Environmental Medicine. 2008;50(4):40110.

[50] Gorman GH, Eide M, Hisle-Gorman E. Wartime Military Deployment and Increased Pediatric Mental and Behavioral Health Complaints. Pediatrics. 2010.

[51] Hoge CW, Auchterlonie JL, Milliken CS. Mental health problems, use of mental health services, and attrition from military service after returning from deployment to Iraq or Afghanistan. JAMA. 2006;295(9):1023-32.

[52] Kessler RC, Chiu WT, Demler O, Walters EE. Prevalence, severity, and comorbidity of 12-month DSM-IV disorders in the National Comorbidity Survey Replication. Archives of General Psychiatry. 2005;62(6):617-27.

[53] Thomas JL, Wilk JE, Riviere LA, McGurk D, Castro CA, Hoge CW. Prevalence of Mental Health Problems and Functional Impairment Among Active Component and National Guard Soldiers 3 and 12 Months Following Combat in Iraq. Arch Gen Psychiatry. 2010;67(6):614-23.

[54] Verdeli H, Baily C, Vousoura E, Belser A, Singla D, \& Manos, G. The case for treating depression in military spouses. Journal of Family Psychology. 2011;25(4):488-96.

[55] Wilcox SL. Social relationships and PTSD symptomatology in combat veterans. Psychological Trauma: Theory, Research, Practice, and Policy. 2010;2(3):175-82.

[56] Reddy MK, Meis LA, Polusny MA, Erbes CR, Compton JS. Associations among experiential avoidance, couple adjustment, and interpersonal aggression in returning Iraqi war veterans and their partners. Journal of Consulting \& Clinical Psychology. 2011;79:515-20.

[57] Kline A, Falca-Dodson M, Sussner B, Ciccone DS, Chandler $\mathrm{H}$, Callahan L, et al. Effects of Repeated Deployment to Iraq and Afghanistan on the Health of New Jersey Army National Guard Troops: Implications for Military Readiness. American Journal of Public Health. 2010;100(2):276-83.

[58] Gerwitz AH, Polusny MA, DeGarmo DS, Khaylis A, Erbes CR. Posttraumatic stress symptoms among National Guard soldiers deployed to Iraq: associations with parenting behaviors and couple adjustment. Journal of Consulting \& Clinical Psychology. 2010;78(5):599-610.

[59] Mullahy J, Sindelar J. Employment, unemployment, and problem drinking. Journal of Health Economics. 1996;15(4): 409-34.

[60] Riviere LA, Kendall-Robbins A, McGurk D, Castro CA, Hoge CW. Coming home may hurt: risk factors for mental ill health in US reservists after deployment in Iraq. The British journal of psychiatry: The Journal of Mental Science. 2011;198(2):136-42.

[61] Warner CH, Appenzeller GN, Grieger T, Belenkiy S, Breitbach J, Parker J, et al. Importance of anonymity to encourage honest reporting in mental health screening after combat deployment. Archives of General Psychiatry. 2011;68(10):106571. 